\title{
Comparison of periodontal disease prevalence among the privileged and the underprivileged tribes of Wayanad, Kerala: A cross sectional study
}

\author{
Shanavas Palliyal ${ }^{1}$, Pradeep PS ${ }^{2 *}$, Anoop $\mathrm{M}^{3}$, Arya Mangal ${ }^{4}$ \\ ${ }^{\mathbf{1}}$ Associate Professor, ${ }^{2}$ Professor, ${ }^{\mathbf{3}}$ Assistant Professor, ${ }^{\mathbf{4}}$ Junior Resident, Dept. of Dentistry, DM WIMS Medical College, Wayanad, \\ Kerala, India
}

*Corresponding Author: Pradeep PS

Email: drpradeep.paisari@gmail.com

\begin{abstract}
Aim and Objective: To determine the periodontal health disparities among privileged and underprivileged tribes of Waynad, Kerala. Materials and Methods: A cross sectional survey was done among 600 Kurichiya and 400 Paniya tribal populations of Wayanad District, Kerala from January 2015 to June 2015 after approval from the Institutional ethical committee. A pretested structured questionnaire was used to collect data regarding study variables. Community Periodontal Index (CPI) was used to record the periodontal status of the study population after obtaining informed consent.

Results: In this study periodontal disease was found to be far more prevalent among the underprivileged Paniyas than among the privile ged Kurichiyas ( $\mathrm{P}<0.0001)$. The prevalence of severe periodontitis was found to be $42 \%$ amongst the Paniyas. This was much higher than the $27 \%$ found among the Kurichiyas, and the national average of $25 \%$. Among the Paniyas a statistically significant relationship was observed between periodontitis and poor access to oral health care $(\mathrm{P}<0.001)$.

Conclusion: The present study demonstrates gross disparities in periodontal health status among the privileged and the underprivileged tribes of Wayanad and the need for active health interventions to eliminate such disparities.
\end{abstract}

Keywords: Periodontal Diseases, Paniya Tribes, Kurichiya Tribes, Disparities, Wayanad, Cross sectional study.

\section{Introduction}

In Wayanad, Kerala the indigenous populations which mainly includes Adivasi or Scheduled Tribe (STs) are the poorest and most marginalized. All India level government data show, Scheduled tribes have higher mortality rates when compared to other sections of the population even after implementation of government schemes for uplifting their socioeconomic standards. ${ }^{1}$ This findings are direct indications that, scheduled tribe populations face more risks of ill health compared to other social groups. Among other things, they are more likely to have tobacco dependence and consume alcohol, and they have higher rates of morbidity. Despite of more than 50 years of affirmative action by the Indian government, large disparities in health and well-being persist between STs and the rest of the population.

Wayanad district in Kerala state is a region in which $17 \%$ of the population is represented by tribal groups. ${ }^{2}$ These tribes generally live under severe socio-economically deprived conditions. Paniya and Kuruchya are two among the major tribal groups which numerically represents the tribal population of Wayanad district. Though the Paniya are highly underprivileged in every aspects of their life, the Kuruchya are comparatively a highly advantaged group in terms of literacy, access to health care and other living conditions.

The oral health of tribal communities living in isolated areas differs in comparison to general population. It is well documented that primitive population are least vulnerable to dental caries in isolated cases, but after their exposure to civilization, they show exaggerated proneness to it. Unlike periodontal disease, dental caries has proved to be one by product of affluence and civilization. The evidence of it is amply exemplified in case of Inuit in Alaska, Ethiopia, Nigeria and Tristan da cunha. ${ }^{3}$ Studies have shown that oral health status among Bhil tribes in Rajasthan, India has high incidence of periodontal disease. ${ }^{4}$

Studies undertaken in this country indicate that the primitive tribals have distinct oral health problems, mainly governed by multidimensional factors like their habitat, different terrain, ecologically variable niches, illiteracy, poverty, isolation and superstition. ${ }^{5}$ The aim of this study was to explore periodontal health disparities among the underprivileged Paniya and the privileged Kurichiya tribes of Wayanad.

\section{Materials and Methods}

A cross sectional survey was done among 600 Kurichiya and 400 Paniya tribal populations of Wayanad District, India from January 2013 to June 2013 after approval from the Institutional ethical committee.

The methodology described by World Health Organization in the book "Oral Health Surveys - Basic Method 4th edition" was followed. ${ }^{4}$ Permission to examine the tribes and the recent health records was obtained from the District Medical Office, Kalpetta. Wayanad District. The study was carried out in 6 weeks during May and June 2015.The clinical examination of all the subjects was done by a single examiner (i.e, investigator himself). Investigator wore disposable mouth masks and disposable gloves during examination.

A pretested structured questionnaire was used to collect data regarding study variables. Community Periodontal Index (CPI) was used to record the periodontal status of the study population after obtaining informed consent. Stratification was done according to age and the following 'Index Age Groups' were considered 35-44yrs, 65-74yrs (in consistent with W.H.O pathfinder methodology). 


\section{Results}

The present study was conducted to assess the oral health status and treatments needs among Paniya and Kuruchya group of tribals of Wayanad district of Kerala state. The survey was carried out using WHO oral health assessment performa the data obtain from the study was subjected to statistical analysis showed the following observation.

The study sample consisted of about 1000 population stratified in to two different age groups of 35 to 44 years and 65 to 74 years of age groups. Among the Kuruchya population $(79.8 \%)$ were $34-44$ years age groups, and $(20.1 \%)$ were $65-74$ years age group.

A total of (82\%) of Paniya population were 35-44 years age groups and (18\%) were 65-74 years age group (Table 1). Among the Kuruchya population $(67.8 \%)$ were males and $(32.1 \%)$ were females. Whereas (53\%) were males and (47\%) were females among Paniya subject (Table 1 and 2).

Periodontal status was assessed using community periodontal index. In the present study Kuruchya population was observed with bleeding on probing (16.8\%) and (5\%) of population had calculus while periodontal pocket of 4 to 5 $\mathrm{mm}$ were detected in $(2.17 \%)$ of population.

In Paniya population score bleeding on probing was observed for $(12.2 \%)$ population. Calculus was observed in (23.5\%) of population. Shallow pocket of 4 to $5 \mathrm{~mm}$ were detected in $(5.25 \%)$ of population. Deep pockets were observed in only (3.5\%) of population (Table 3, Fig. 1).

In the present study it was observed that in the study subjects that the mean number of sextants with healthy (score 0 ) was more among Kuruchya population (5.28) compared to Paniya population (4.51). While bleeding (score 1) was more in Kuruchya population (0.45) compared to Paniya population (0.28). Score 2 was more in Paniya population (0.96) compared to $(0.18)$ in Kuruchya population. The mean score for shallow pocket of $4-5 \mathrm{~mm}$ (score 3) was (0.02) in Kuruchya population and (0.07) was observed in Paniya population (Table 4).

When periodontal status of Kuruchya population according to loss of attachment was assessed, it was observed that the highest proportion of population $(96.5 \%)$ with loss of attachment of $0-3 \mathrm{~mm}$ and loss of attachment of $4-5 \mathrm{~mm}$ was recorded $(2.67 \%)$. It was observed that $(0.17 \%)$ of population had loss of attachment of 6-8mm and $(0 \%)$ of population had loss of attachment of $9-11 \mathrm{~mm}$.
In Paniya population the loss of attachment $0-3 \mathrm{~mm}$ was recorded in the $(90.5 \%)$ of them, loss of attachment of $4-5 \mathrm{~mm}$ was $(5.25 \%)$ of population $(2.25 \%)$ of population had no loss of attachment of $6-8 \mathrm{~mm},(0.5 \%)$ population had loss of attachment of $9-11 \mathrm{~mm}$. Loss of attachment of $12 \mathrm{~mm}$ or more detected in $(0.75 \%)$ of population. A statistically significant association ( $p<0.001)$ was observed (Table 5, Fig. 2).

The mean number of sextant with loss of attachment 0 $3 \mathrm{~mm}$ (score 0) in Kuruchya population was (5.90), among Paniya population it was observed as (5.73). The mean number of sextant with loss of attachment 4-5mm (score 1) was higher in Paniya population (0.12) compared to Kuruchya population (0.04) loss of attachment of 6-8mm (score 2) was observed more in Paniya population (0.03) compared to Kuruchya (0.001) population. The loss of attachment of $9-11 \mathrm{~mm}$ (score 3) was recorded (0) in Kuruchya population where as in Paniya population it was observed to be (0.007). The excluded sextant (score $\mathrm{x}$ ) was higher among Paniya population (0.08) compared to Kuruchya population (0.03) (Table 6).

Table 1: Distribution of Paniya and Kuruchya population by age group

\begin{tabular}{|c|c|c|}
\hline Age (in years) & $\mathbf{3 5 - 4 4}$ & $\mathbf{6 5 - 7 4}$ \\
& $\mathbf{N}(\mathbf{\%})$ & $\mathbf{N}(\mathbf{\%})$ \\
\hline Kuruchya tribes & 479 & 121 \\
& $(79.8)$ & $(20.1)$ \\
\hline Paniya tribes & 328 & 72 \\
& $(82)$ & $(18)$ \\
\hline Total & 807 & 193 \\
& $(80.7)$ & $(19.3)$ \\
\hline
\end{tabular}

Table 2: Distribution of Paniya and Kuruchya population by sex

\begin{tabular}{|c|c|c|}
\hline Gender & $\begin{array}{c}\text { Male } \\
\mathbf{N}(\%)\end{array}$ & $\begin{array}{c}\text { Female } \\
\mathbf{N}(\%)\end{array}$ \\
\hline Kuruchya tribes & 407 & 193 \\
& $(67.83)$ & $(32.1)$ \\
\hline Paniya tribes & 212 & 188 \\
& $(53)$ & $(47)$ \\
\hline Total & 619 & 381 \\
& $(61.9)$ & $(38.1)$ \\
\hline
\end{tabular}

Table 3: Percentage of Kuruchya population with healthy periodontal tissue; percentage of the population with bleeding only; percentage of population with calculus: percentage of population with shallow pockets; percentage of population with deep pockets

\begin{tabular}{|c|c|c|c|c|c|c|c|c|}
\hline \multicolumn{2}{|c|}{ Highest CPI Score } & \multirow{2}{*}{$\begin{array}{c}\begin{array}{c}\text { Healthy } \\
\text { (score 0) }\end{array} \\
77.4 \\
\end{array}$} & \multirow{2}{*}{$\begin{array}{c}\begin{array}{c}\text { Bleeding } \\
\text { (score 1) }\end{array} \\
17.1 \\
\end{array}$} & \multirow{2}{*}{$\begin{array}{c}\begin{array}{c}\text { Calculus } \\
\text { (score 2) }\end{array} \\
4.3 \\
\end{array}$} & \multirow{2}{*}{$\begin{array}{c}\begin{array}{c}\text { Pocket 4- } \\
\mathbf{5} \text { mm } \\
\text { (score 3) }\end{array} \\
1.04 \\
\end{array}$} & \multirow{2}{*}{$\begin{array}{c}\begin{array}{c}\text { Pocket } 6 \text { mm } \\
\text { or more } \\
\text { (score 4) }\end{array} \\
0 \\
\end{array}$} & \multirow{2}{*}{$\begin{array}{c}\begin{array}{c}\text { Excluded } \\
\text { (score X) }\end{array} \\
0.2\end{array}$} & \multirow{2}{*}{$\begin{array}{c}\begin{array}{c}\text { Not } \\
\text { recorded } \\
\text { (score 9) }\end{array} \\
0\end{array}$} \\
\hline $35-44$ years $(479)$ & $\begin{array}{l}\mathrm{N} \\
(\%)\end{array}$ & & & & & & & \\
\hline $\begin{array}{l}\text { 65-74 years } \\
(121)\end{array}$ & $\begin{array}{c}\mathrm{N} \\
(\%)\end{array}$ & 66.9 & 15.7 & 7.43 & 6.61 & 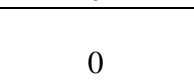 & 1.65 & 1.65 \\
\hline \multirow[t]{2}{*}{ Total } & $\mathrm{N}$ & \multirow[t]{2}{*}{75.3} & \multirow[t]{2}{*}{16.83} & \multirow[t]{2}{*}{5.00} & \multirow{2}{*}{2.17} & \multirow[t]{2}{*}{0.0} & 0.33 & \multirow[t]{2}{*}{0.33} \\
\hline & $(\%)$ & & & & & & & \\
\hline
\end{tabular}


Table 4: The Mean number of sextants with healthy periodontal tissues, bleeding or higher score, calculus or higher score, shallow pockets or higher score, deep pockets in Paniya and Kuruchya population

\begin{tabular}{|c|c|c|c|c|c|c|c|c|}
\hline \multicolumn{2}{|c|}{} & $\begin{array}{c}\text { Healthy } \\
\text { (score 0) }\end{array}$ & $\begin{array}{c}\text { Bleeding } \\
\text { (score 1) }\end{array}$ & $\begin{array}{c}\text { Calculus } \\
\text { (score 2) }\end{array}$ & $\begin{array}{c}\text { Pocket 4 - } \\
\mathbf{5 ~ m m} \\
\text { (score 3) }\end{array}$ & $\begin{array}{c}\text { Pocket 6 } \\
\text { mm or } \\
\text { more } \\
\text { (score 4) }\end{array}$ & $\begin{array}{c}\text { Excluded } \\
\text { (score X) }\end{array}$ & $\begin{array}{c}\text { Not } \\
\text { recorded } \\
\text { (score 9) }\end{array}$ \\
\hline $\begin{array}{c}\text { Kuruchya } \\
\text { tribes }\end{array}$ & Mean & 5.28 & 0.45 & 0.18 & 0.02 & 0 & 0.02 & 0.02 \\
\hline $\begin{array}{c}\text { Paniya } \\
\text { tribes }\end{array}$ & Mean & 1.29 & 1.05 & 0.51 & 0.33 & 0 & 0.41 & 0.41 \\
\cline { 2 - 9 } & SD & 1.51 & 0.28 & 0.96 & 0.07 & 0.04 & 0.08 & 0 \\
\hline
\end{tabular}

Table 5: Number and percentage of Paniya population with loss of attachment by highest score

\begin{tabular}{|c|c|c|c|c|c|c|c|c|}
\hline \multicolumn{2}{|c|}{$\begin{array}{l}\text { Highest LOA } \\
\text { Score }\end{array}$} & \multirow{2}{*}{$\begin{array}{c}\begin{array}{c}\text { Loss of } \\
\text { attachment } \\
\mathbf{0 - 3} \mathbf{~ m m}\end{array} \\
308 \\
(93.9)\end{array}$} & \multirow{2}{*}{$\begin{array}{c}\begin{array}{c}\text { Loss of } \\
\text { attachment } \\
\mathbf{4 - 5} \mathbf{~ m m}\end{array} \\
13 \\
(3.9)\end{array}$} & \multirow{2}{*}{$\begin{array}{c}\begin{array}{c}\text { Loss of } \\
\text { attachment } \\
\mathbf{6 - 8} \mathbf{~ m m}\end{array} \\
5 \\
(1.52)\end{array}$} & \multirow{2}{*}{$\begin{array}{c}\begin{array}{c}\text { Loss of } \\
\text { attachment } \\
9-11 ~ \mathbf{~ m m}\end{array} \\
0 \\
(0)\end{array}$} & \multirow{2}{*}{$\begin{array}{c}\begin{array}{c}\text { Loss of } \\
\text { attachment } \\
\mathbf{1 2} \text { mm or } \\
\text { more }\end{array} \\
1 \\
(0.30)\end{array}$} & \multirow{2}{*}{$\begin{array}{c}\begin{array}{c}\text { Excluded } \\
\text { sextant }\end{array} \\
1 \\
(0.3)\end{array}$} & \multirow{2}{*}{$\begin{array}{c}\begin{array}{c}\text { Not } \\
\text { recorded }\end{array} \\
\\
0 \\
(0.0)\end{array}$} \\
\hline $\begin{array}{l}35-44 \\
\text { years } \\
(328)\end{array}$ & $\begin{array}{c}\mathrm{N} \\
(\%)\end{array}$ & & & & & & & \\
\hline $\begin{array}{l}65-74 \\
\text { years } \\
(72)\end{array}$ & $\begin{array}{l}\mathrm{N} \\
(\%)\end{array}$ & $\begin{array}{c}54 \\
(75)\end{array}$ & $\begin{array}{c}8 \\
(11.1)\end{array}$ & $\begin{array}{c}4 \\
(5.55)\end{array}$ & $\begin{array}{c}2 \\
(2.77)\end{array}$ & $\begin{array}{c}2 \\
(2.77)\end{array}$ & $\begin{array}{c}2 \\
(2.7)\end{array}$ & $\begin{array}{c}0 \\
(0.0)\end{array}$ \\
\hline Total & $\begin{array}{c}\mathrm{N} \\
(\%) \\
\end{array}$ & $\begin{array}{c}362 \\
(90.5)\end{array}$ & $\begin{array}{c}21 \\
(5.25)\end{array}$ & $\begin{array}{c}9 \\
(2.25)\end{array}$ & $\begin{array}{c}2 \\
(0.50)\end{array}$ & $\begin{array}{c}3 \\
(0.75)\end{array}$ & $\begin{array}{c}3 \\
(0.75) \\
\end{array}$ & $\begin{array}{c}0 \\
(0.0)\end{array}$ \\
\hline
\end{tabular}

Table 6: The Mean number of sextants with loss of attachments by score; mean number of sextants excluded from examination; mean number of sextants not recorded in Paniya and Kuruchya population

\begin{tabular}{|c|c|c|c|c|c|c|c|c|}
\hline & & $\begin{array}{c}\text { Loss of } \\
\text { attachme } \\
\text { nt } 0-3 \\
\text { mm } \\
\text { (score } 0 \text { ) }\end{array}$ & $\begin{array}{c}\text { Loss of } \\
\text { attachment } \\
4-5 \mathrm{~mm} \\
\text { score 1) }\end{array}$ & $\begin{array}{c}\text { Loss of } \\
\text { attachment } \\
6-8 \mathrm{~mm} \\
\text { (score 2) }\end{array}$ & $\begin{array}{c}\text { Loss of } \\
\text { attachment } \\
9-11 \mathrm{~mm} \\
\text { (score 3) }\end{array}$ & $\begin{array}{c}\text { Loss of } \\
\text { attachment } 12 \\
\text { mm or more } \\
\text { (score 4) }\end{array}$ & $\begin{array}{c}\text { Excluded } \\
\text { sextant } \\
\text { (score X) }\end{array}$ & $\begin{array}{c}\text { Not } \\
\text { recorded } \\
\text { (score 9) }\end{array}$ \\
\hline \multirow{2}{*}{$\begin{array}{l}\text { Kuruchya } \\
\text { tribes }\end{array}$} & Mean & 5.9 & 0.04 & 0.001 & 0 & 0 & 0.03 & 0.02 \\
\hline & SD & 1.23 & 0.90 & 0.41 & 0 & 0 & 0.34 & 065 \\
\hline \multirow{2}{*}{$\begin{array}{c}\text { Paniya } \\
\text { tribes }\end{array}$} & Mean & 5.73 & 0.12 & 0.03 & 0.006 & 0.007 & 0.087 & 0 \\
\hline & SD & 1.62 & 0.64 & 0.33 & 0.02 & 0.02 & 1.02 & 0 \\
\hline
\end{tabular}

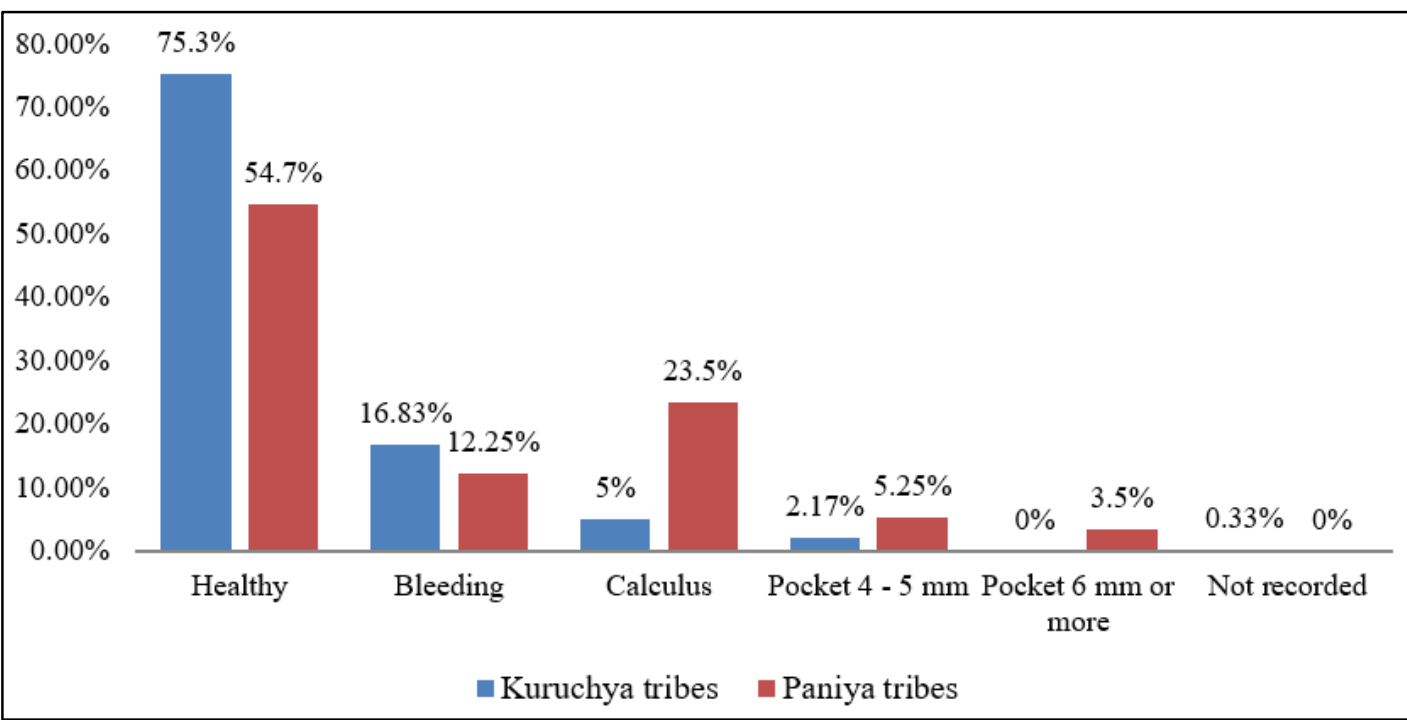

Fig. 1: Percentage of Paniya and Kuruchya population with healthy periodontal tissue; percentage of the subjects with bleeding only; percentage of subjects with calculus: percentage of subjects with shallow pockets; percentage of subjects with deep pockets 


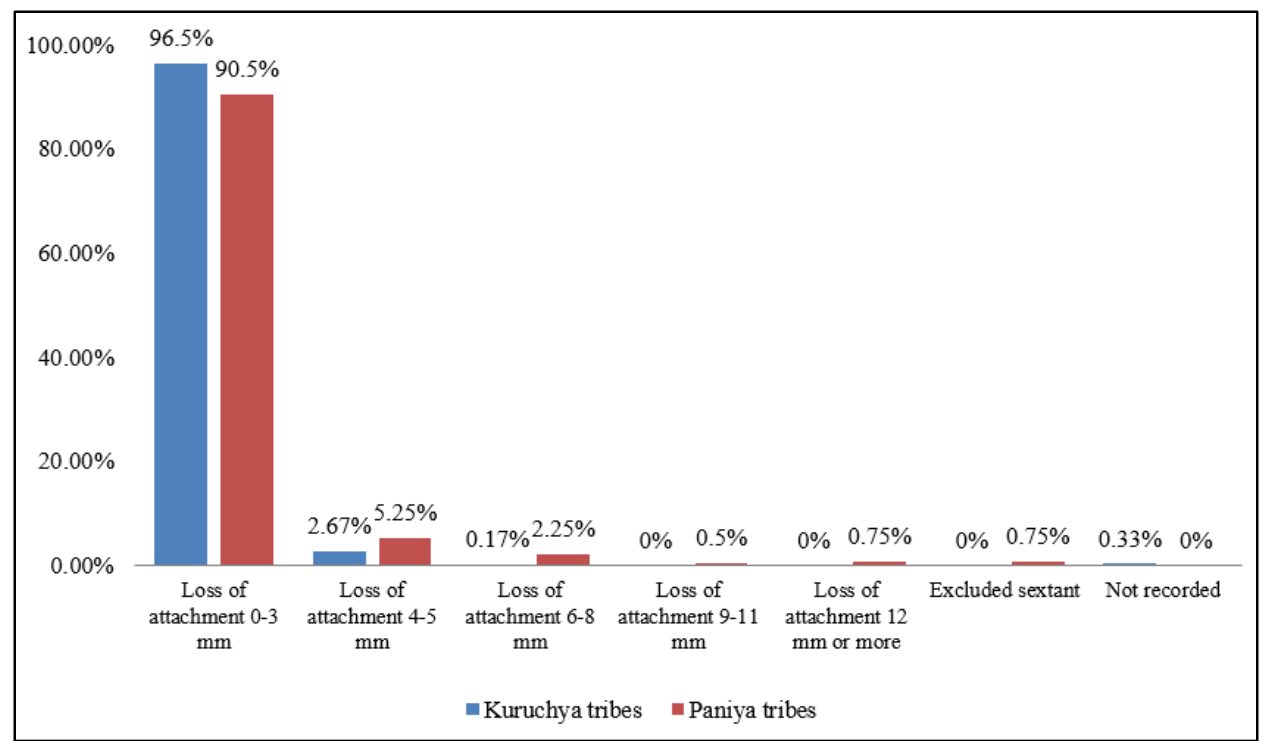

Fig. 2: Number and percentage of Paniya and Kuruchya population with loss of attachments by highest score

\section{Discussion}

Tribal population of India is part and parcel of Indian population. A tribal society is a self-sufficient group, having their own economic, political, religious and social institutions. They form a social group usually with a definite area, dialect, cultural homogeneity and unifying social organization. ${ }^{6}$

Wayanad is one of the important tribal belts of Kerala. Epidemiological studies have concluded that tribal populations in Wayanad face more risks of ill health compared to other social groups; among other things, they are more likely to use tobacco and consume alcohol, and they have higher rates of morbidity. Despite of, years of affirmative action by the government, large disparities in health and well-being persist among tribal populations. ${ }^{7}$

The present study deals with the periodontal health status among Paniya and Kuruchya tribal community of Wayanad, Kerala State. Who have been discriminated and marginalized due to several historical, cultural and socio-economic reasons. The study was carried out in 6 weeks during May and June 2015. The WHO Oral Health Assessment Form (1997) was used for the survey. This survey was done to assess the prevalence of periodontal status as per CPI, and loss of attachment. With this information future programs can be developed to improve the oral health of these populations.

The study sample consisted about 1000 subjects. They were examined according to the WHO 1997, 'Basic Oral Health Survey Methods'. Based on the inclusion and exclusion criteria two tribal communities (Paniya and Kuruchya) were selected. The Paniya and Kuruchya populations stratified in to two different groups of 35 to 44 years and 65 to 74 years age groups, in which 35 to 44 age group is the standard monitoring group for health condition of the adults whereas 65 to 74 years of study population is the standard monitoring group for the health condition of elderly. ${ }^{8}$
Totally valid comparisons of the present study with other studies is difficult due to differences in the type of population, selected age group and the period during which studies were conducted. However an attempt has been made to compare with similar studies conducted in other population groups.

The Kuruchya and Paniya population in the present study were assumed to share a similar socio economic status since they reside in the hilly terrain that are not easily accessible by road. The Paniya populations live in colonies (clusters of houses in a small geographical area) in peripheral areas; they rarely interact socially outside their own colony. Colonies have poor transportation linkages and are particularly vulnerable to flooding during monsoons. ${ }^{9}$

Majority of the Kuruchya population were involved in agriculture $(80 \%)$ or daily wage labour $(18 \%)$ which is the major occupation of rural Kerala. The Paniya community is predominantly landless, only $(2.2 \%)$ were involved in agriculture (44\%) of them were involved in wage labour and (31\%) of Paniya population were registered in NREGS scheme.

It was very interesting to note that $(22.7 \%)$ of Paniya population were unemployed where as only $(0.17 \%)$ of Kuruchya population were unemployed. A study by Nazer M et $\mathrm{al}(2009)^{10}$ in their study observed that the economy of Paniyas is well-knit with that of the non-tribal settlers who control their occupational pattern and thereby influencing their economic conditions. Since they are employed for agricultural operations like sowing and harvesting only, they have to remain as unemployed for a period of 3 to 4 months.

A study by Mohindra KS et al $(2010)^{6}$ observed that Paniya spend a significant proportion of their household income on alcohol and tobacco, which represent $17 \%$ of total expenditure on food consumption. This could probably explain the increased prevalence of periodontities observed in the Paniya population can hence be attributed to habits prevalent in the community. 
According to Mohindra KS et al $(2010)^{6}$ betal quid chewing among Paniyas is considered an auspicious ingredient of their culture. Thus the increased prevalence of periodontities and leukoplakia among Paniya population could be due to smoking and betal quid chewing habits.

In the present study the periodontal status of the population was examined as per CPI, it was observed that the maximum number of population scoring healthy sextants was found in 35-44 years age group and values gradually increased as age increased.

The prevalence of periodontitis was observed to be higher among Paniya population compared to Kuruchya population. Presence of calculus dominated as most common periodontal condition among Paniya tribal population $(23.5 \%)$. Which is in accordance with the study conducted by Benoit Verenne, Poul et al (2004). ${ }^{7}$ The increased prevalence of calculus may be due to the widespread use of arecanut by the Paniya tribals. Previous studies by Amersena $\mathrm{N}$ et al(2002) showed that arecanut chewing can lead to calculus formation.

The periodontal status of the Paniya population is comparable to that of the adult southern Chinese. Corbet EF et al $(2001)^{11}$ in their study found presence of calculus as most common periodontal finding in $61 \%$ of $33-44$ years old population.

In the present study the mean score for shallow pockets and deep pockets in Paniya population were $(5.25 \%)$ and (3.5\%) respectively. Corbet EF et al (2001) in their study shallow pockets were found as the highest CPI score in one third of subjects and deep pockets in 3\% of the subjects, which is in close agreement with the observation of our study. Galan D et al(1993) $)^{12}$ in their study on Canadian inuits consisting of elders of above 60 years at age revealed that $86 \%$ of them had shallow and deep pockets which is not in occurrence with the results of the current study.

The destructive and degenerative nature of periodontal disease was assessed by loss of attachment. The loss of attachment was observed to be more prevalent in 65-74 years of age group. In our study 35-44 years old Paniya population $(3.9 \%)$ and $(2.5 \%)$ of Kuruchya population had loss of attachment of 4-6 mm. According to the Stjepan Spalj et al ${ }^{13}$ in their study $50 \%$ of the 35+ age groups had loss of attachment more than $6 \mathrm{~mm}$, this is not accordance with our study.

Sehamschula R.G et al $(1980)^{14}$ have shown that people in developing countries have limited access to dental care, more periodontal disease and higher levels of plaque and calculus than people in more economically developed societies. This is certainly true for the present study group for whom dental health services are virtually nonexistent. Oral disease remains largely untreated in this population.

In this present study Paniya and Kuruchya population showed a high prevalence of oral mucosal lesions, dental caries and periodontal diseases. This may be explained due to various factors like socio-economic conditions, diet and oral hygiene practices. And also may be due to virtual absence of accessibility and affordability to oral health care facilities among the population.Conclusion

The observations of the present study showed that periodontal health disparities appear to be more pronounced among Paniya tribes than among Kuruchyas. The unmet treatment need of the Paniya community may be due to lower affordability of dental care in the private sector and less positive attitude towards oral health. Hence attention should be focused on improving the oral health status and treatment needs of the Paniya community. More research is needed to interpret the factors that contribute to these inequalities and to develop specific interventions to increase access and utilization among tribal populations.

\section{Source of Funding}

None.

\section{Conflict of Interest}

None.

\section{References}

1. Demographics of India. Scheduled tribes population districtcensus 2011 report.

2. Paula J. From classic texts to learned practice; methodological remarks on the study of Indian medicine. Soc Sci Med. 1978;12:97-103

3. Kumar S. Oral health status and practices of denate Bhil adult tribes of Southern Rajasthan, India. Int Dent J. 2009;59:13340 .

4. World Health organization. Oral Health Surveys-basic methods. $4^{\text {th }}$ Edition.

5. ICMR Bulletin. Health Status of primitive tribes of Orissa. A report submitted to the Planning Commission. New Delhi. 2003.

6. Bhasin V. Oral Health Behaviour among Bhils of Rajasthan. $J$ Soc Sci. 2004;8(1):1-5.

7. Poul Erik Petersen, John Clarkson, Martin Hobdell. Global goals for oral health 2020. Int Dent J. 2003;53:285-8.

8. www.scribd.com/doc/40/wayanad-initiative. Accessed 20/05/2017

9. Rajashekaran G. Wayanad District. Department of information and public relations government of Kerala; 2007 (Accessed 18/06/11)

10. Nazer M. A study of land alienation and indebtedness among tribals in Tamil Nadu, Kerala and Karnataka states". (vol.12) modern publications. Calicut; 2009.

11. Corbet EF, Wong MCM, Lin HC. Periodontal conditions in adult southern. Chinese J Dent Res. 2001;80(5):1480-5.

12. Galan D, Odlum O, Brecx M. Oral health status of a group of elderly Canadian Inuit (Eskimo). Community Dent Oral Epidemiol. 1993:21:53-6.

13. Spalj S, Plancak D. Comparison of periodontal health in two different rural population types in croatia. Acta Stomatol Croat. 2000;34(2):183-7.

14. Sehamschula RG, Cooper MH. Oral health of adolescent and adult Australian Aborigines. Community Dent Oral Epidemiol. 1978;8:370-4

How to cite this article: Palliyal S, Pradeep PS, Anoop M, Mangal A. Comparison of periodontal disease prevalence among the privileged and the underprivileged tribes of Wayanad, Kerala: A cross sectional study. Int J Oral Health Dent 2020;6(1):22-6. 